\title{
Cluster formation at the Si/liquid interface in Sr and Na modified Al-Si alloys
}

Jenifer Barrirero, Jiehua Li, Michael Engstler, Naureen Ghafoor, Peter Schumacher, Magnus

Odén and Frank Muecklich

\section{Linköping University Post Print}

\section{Tweet}

N.B.: When citing this work, cite the original article.

Original Publication:

Jenifer Barrirero, Jiehua Li, Michael Engstler, Naureen Ghafoor, Peter Schumacher, Magnus Odén and Frank Muecklich, Cluster formation at the Si/liquid interface in $\mathrm{Sr}$ and Na modified Al-Si alloys, 2016, Scripta Materialia, (117), 16-19.

http://dx.doi.org/10.1016/j.scriptamat.2016.02.018

Copyright: Elsevier

http://www.elsevier.com/

Postprint available at: Linköping University Electronic Press

http://urn.kb.se/resolve?urn=urn:nbn:se:liu:diva-127548 


\section{Cluster formation at the $\mathrm{Si} /$ liquid interface in $\mathrm{Sr}$ and $\mathrm{Na}$ modified}

\section{Al-Si alloys}

Jenifer Barrireroa,b, Jiehua Lic, Michael Engstlera, Naureen Ghafoorb, Peter Schumacherc, Magnus Odén ${ }^{\mathrm{b}}$, Frank Mücklich ${ }^{\mathrm{a}}$

${ }^{a}$ Chair of Functional Materials, Department of Materials Science, Campus D3.3, Saarland University, D 66123 Saarbrücken, Germany

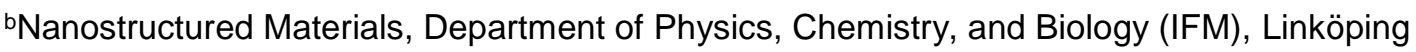
University, SE 58183 Linköping, Sweden

'Chair of Casting Research, Montanuniversität Leoben, A 8700, Leoben, Austria

Graphical abstract
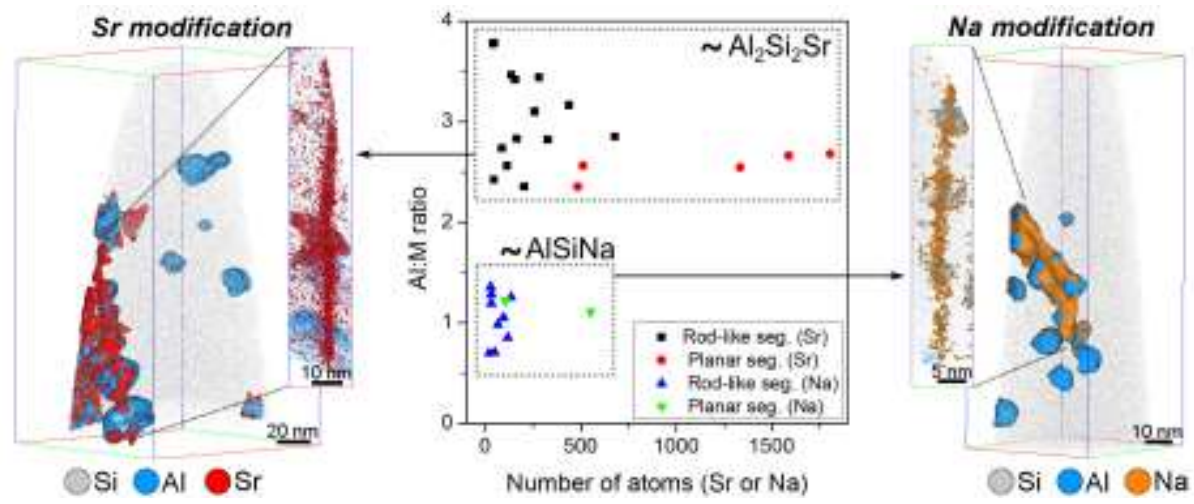

\section{Abstract}

Atom probe tomography was used to compare $\mathrm{Na}$ and $\mathrm{Sr}$ modified $\mathrm{Al}-\mathrm{Si}$ hypoeutectic alloys. Both $\mathrm{Na}$ and Sr promote the formation of nanometer-sized clusters in the Si eutectic phase. Compositional analyses of the clusters show an Al:Sr ratio of $2.92 \pm 0.46$ and an Al:Na ratio of $1.07 \pm 0.23$. It is proposed that $\mathrm{SrAl}_{2} \mathrm{Si}_{2}$ and $\mathrm{NaAISi}$ clusters are formed at the $\mathrm{Si}$ / liquid interface and take part in the modification process by altering the eutectic Si growth.

To meet the evolving demands of current high-performance industrial applications, ultimate tensile strength, ductility, impact and thermal-shock properties of Al-Si alloys can be effectively favoured by a 
morphological modification of the eutectic phase [1]. $\mathrm{Na}$ and $\mathrm{Sr}$ are known to segregate into the eutectic Si phase and effectively induce a transition from a plate- to a coralline-like structure [2-5]. Since Pacz discovered this effect in 1921 [6], large efforts have been directed towards understanding the underlying mechanisms. During the first half of last century, Na modification was in focus [7-12]. Later, Sr emerged as an attractive alternative to $\mathrm{Na}$ since it is easier to control the $\mathrm{Sr}$-content during the casting process. Na has high volatility and oxidizes easily, which affects the $\mathrm{Na}$ addition control [8]. Sr has a lower tendency to fade and can be added in the form of Al-Sr master alloys, making the addition of the alloying element easier and more precise [1].

The effects of $\mathrm{Na}$ and $\mathrm{Sr}$ on the morphological modification have often been considered indistinctively [13-15]. Both elements produce multiplication of twins and lattice defects in the Si phase, as well as the same coralline-like eutectic microstructure.

Recent investigations have revealed that $\mathrm{Al}$ forms segregations with $\mathrm{Sr}$ or $\mathrm{Na}$ in the $\mathrm{Si}$ eutectic phase [16-18]. The presence of Al in combination with the modifier was not considered in previous theories when explaining the origin of the modification $[5,11]$. These findings open for new interpretations on the role of $\mathrm{Al}$ and the mechanisms causing the change in the microstructure.

In this paper, atom probe tomography (APT) combined with transmission electron microscopy (TEM) is used to compare the structure and the Al content in Sr- and Na-rich clusters in the Si eutectic phase. It is proposed that $\mathrm{SrAl}_{2} \mathrm{Si}_{2}$ and $\mathrm{NaAlSi}$ clusters form at the $\mathrm{Si} /$ liquid interface and take part in the modification of the eutectic Si growth to form a coralline-like microstructure.

Al-Si hypoeutectic alloys modified with $\mathrm{Sr}$ and Na were manufactured by high purity $\mathrm{Si}(5 \mathrm{~N}, 99.999)$ and $\mathrm{Al}(5 \mathrm{~N})$. An Al-5 wt.\% Si alloy was modified by $160 \mathrm{ppm} \mathrm{Na}$. Na was added using elemental $\mathrm{Na}$ in vacuum packed Al foils before casting. An Al-7 wt.\% Si alloy was modified by $150 \mathrm{ppm} \mathrm{Sr}$ added using an $\mathrm{Al}-10$ wt.\% Sr master alloy.

TEM sample preparation was performed by successive mechanical grinding, polishing, and dimpling to a thickness of about $30 \mu \mathrm{m}$ followed by Ar ion-beam milling to electron transparency using a Gatan Precision lon Polishing System (PIPS) model 691. Additional TEM and APT samples were prepared in a dual-beam focused ion beam / scanning electron microscopy workstation (FIB/SEM) (Helios NanoLab $600^{\mathrm{TM}}$, FEI Company, USA). After lift out and thinning of the samples, a low energy milling at $2 \mathrm{kV}$ was performed to minimize gallium induced damage [19]. 
TEM analysis was performed using a FEI Tecnai G2 microscope operated at $200 \mathrm{kV}$ in micro and nanoprobe mode and an image-side aberration-corrected JEOL 2100F microscope operated at 200 kV. Laser Pulsed APT was carried out with a LEAP ${ }^{\mathrm{TM}} 3000 \mathrm{X}$ HR (CAMECA) at repetition rates of 160 $\mathrm{kHz}$ and $250 \mathrm{kHz}$, a specimen temperature of about $40 \mathrm{~K}$, a pressure lower than $1.33 \times 10^{-8} \mathrm{~Pa}$, and a laser pulse energy in the range of $0.4-0.5 \mathrm{~nJ}$. The evaporation rate of the specimen was 5 atoms per 1000 pulses. Datasets were reconstructed and analysed with IVAS ${ }^{\mathrm{TM}} 3.6 .8$ software (CAMECA). Al, Sr and $\mathrm{Na}$ contents in Si were measured after background subtraction performed with the IVAS software. The eutectic Si structure of both alloys, modified either by the addition of $\mathrm{Sr}$ or $\mathrm{Na}$, presents a high density of lattice defects (Figure 1). These defects are necessary for the repeated change of $\mathrm{Si}$ growth direction and growth rate that give rise to the desired coralline-structure [16]. It was observed that the defects in the Si lattice are enriched by the modifier $(\mathrm{Sr} / \mathrm{Na})$ and $\mathrm{Al}$ by correlating TEM and APT data. TEM images in Figure 1 show spherical-precipitates, stacking faults (SFs) and twin lamellas (TLs) which have a one-to-one correspondence to the three categories of solute clusters detected by APT: spherical, rod-like and planar (Figures 2 and 3).

TEM images of both alloys reveal that spherical precipitates are often located at the intersection of SFs and TLs on $\{111\}$ Si planes (Figure $1 \mathrm{~b}, \mathrm{c}$ and d). APT confirms the presence of spherical precipitates and shows solute enrichment of $\mathrm{Al}$ and modifiers (Figure 2). This suggests that the spherical precipitates may assist the formation of SFs and TLs. Based on this, the phenomena causing the modified microstructure appear to be the same for both $\mathrm{Sr}$ and $\mathrm{Na}$ additions, i.e. an obstructed Si growth as a result of the formation of a high number of solute-enriched clusters and crystallographic defects.

Despite the structural similarities between $\mathrm{Sr}$ and Na modifications, it is important to point out a significant difference in the composition of the $\mathrm{Sr}$ - and $\mathrm{Na}$-rich clusters recorded by APT. Since the clusters are located in the Si phase, their Si content could not be determined and instead the focus was put on the content of $\mathrm{Al}$ and modifier. The local composition of the clusters measured by APT can be influenced by ion trajectory overlaps due to local magnification effects [20]. When considering 2 - 5 nanometre sized segregations present in these alloys, this artefact may lead to a convolution of the matrix with the precipitate resulting in an overestimation of the matrix element [20-24]. Given this uncertainty, reporting relative solute ratios $\mathrm{Al}: \mathrm{M}(\mathrm{M}=\mathrm{Sr}$ or $\mathrm{Na})$ is more adequate than the absolute concentrations. Each single cluster of solutes was exported in tightly fitted regions of interest (ROIs) 
for separate analysis. The bulk composition inside the ROI was measured after optimization of the elemental ranges in the mass-to-charge spectrum. The number of solute atoms in the clusters was measured after background subtraction. Figure 4 shows the Al:M ratios for each cluster. The ratios for Sr- and Na-modified alloys are distinctly different, i.e. the ratio data-sets have no overlap and no outliers. In the Sr-modified alloy, the average of 14 rod-like and 5 planar segregations from 6 APT specimens yields an Al:Sr ratio of $2.92 \pm 0.46$. In the Na-modified alloy, the average of 9 rod-like and 2 planar segregations from 5 APT specimens results in an Al:Na ratio of $1.07 \pm 0.23$. The standard deviations in the Al:M ratios can be attributed to the combined effect of the limited number of solute atoms involved in such small clusters and the detection efficiency of APT ( $37 \%)$. The ratios indicate that $\mathrm{Al}$ is needed to form these segregations and that $\mathrm{Al}$ interacts differently with $\mathrm{Na}$ and $\mathrm{Sr}$. Inferring the role of $\mathrm{Al}$ on the modification and understanding the Al:M ratios is not straight forward given the required extrapolation from an observed "post-mortem" microstructure to the dynamic scenario occurring at a moving solid / liquid interface in a temperature gradient during solidification. The high density of defects has historically been explained by the impurity induced twinning (IIT) mechanism and the poisoning of the twin plane re-entrant edge (TPRE) mechanism suggesting an inhibition of the Si growth by adsorption of single atoms of the modifier at the solid / liquid interface $[5,11]$. This led to the proposal that the atomic radius $(r)$ of the modifiers satisfy a geometrical factor of $r_{M} / r_{S i}=1.646$. However, this way of explaining the origin for modification does not consider the presence of $\mathrm{Al}$ nor the defined $\mathrm{Al}: \mathrm{M}$ ratios found in this investigation.

Recently, Li et al [25] proposed that the adsorption of $\mathrm{Sr}$ (or $\mathrm{Na}$ ) atoms causes the changes in growth direction and multiplication of twins, while the entrainment of Al together with the modifier is an artefact rather than an active factor for the modification. They propose that the formation of Al-Si-Srrich clusters takes place after the adsorption of $\mathrm{Sr}$ (or $\mathrm{Na}$ ) atoms during the subsequent overgrowth of Si. Another way of explaining the presence of Al, however, would be to consider the formation of such clusters at the growth front just before the overgrowth of $\mathrm{Si}$. To address the different $\mathrm{Al}: \mathrm{M}$ ratios, one can first consider the invariant reactions reported in literature for the Al-Si [26], Al-Si-Na [27] and AlSi-Sr [28] systems (Table I). Due to the low concentration of modifier in both systems, they present ternary eutectic reactions very near to the binary Al-Si eutectic composition and temperature (Table I). In the system containing $\mathrm{Na}$, the $\mathrm{NaAISi}(\mathrm{T})$ ternary compound forms together with $\mathrm{Si}$ and $\mathrm{Al}$ [27]; while for the alloy containing $\mathrm{Sr}, \mathrm{SrAl}_{2} \mathrm{Si}_{2}$ phase is predicted [28]. Such compounds are consistent with 
the Al:M ratios measured by APT in the rod-like and planar segregations in the Si phase. The stoichiometry of the clusters (Al: $\mathrm{Na} \sim 1, \mathrm{Al}: \mathrm{Sr} \sim 2$ ) corresponds to the compounds expected for each alloy, i.e. NaAlSi for $\mathrm{Na}$ modification and $\mathrm{SrAl}_{2} \mathrm{Si}_{2}$ for $\mathrm{Sr}$ modification.

In the case of the alloy containing $\mathrm{Sr}$, even though thermodynamic calculations predict the formation of $\mathrm{SrAl}_{2} \mathrm{Si}_{2}$ at the ternary eutectic reaction [28], this will only be possible if there is a local $\mathrm{Sr}$ concentration of about 20 at.\% Sr. Since the content of the modifier in the alloy is much lower, the nucleation and growth of this intermetallic phase will not be always feasible. However, locally at a length scale just involving a few thousand atoms the situation might be dramatically different. Ahead of the growing Si crystal a diffusion profile is formed by segregation leading to constitutional undercooling. The solubilities of $\mathrm{Al}$ and $\mathrm{Sr}$ in $\mathrm{Si}$ are $\sim 400$ at-ppm and $\sim 40$ at-ppm, respectively [16], which is less than the expected concentration in the liquid. Therefore, both these elements are expected to be enriched ahead of the solidification front. That is, over a distance of a few nanometres in front of the growth front, the local concentrations of $\mathrm{Sr}$ and $\mathrm{Al}$ are sufficiently high to allow for the formation of atomic clusters of compounds. Recently, Srirangam et al [29] showed that the local coordination environment of $\mathrm{Sr}$ in $\mathrm{Al}-\mathrm{Si}$ alloys is consistent with the formation of $\mathrm{SrAl}_{2} \mathrm{Si}_{2}$ clusters in the eutectic phase supporting the concept that nanometer-sized clusters can be formed in these alloys. According to the classical homogenous nucleation theory clusters of this size are subcritical, , and the local ordering in the melt would be that of fluctuating clusters. For stable clusters to occur, heterogeneous substrates and / or high undercooling must be present. Thus, during growth of the eutectic $\mathrm{Si}$, two competing processes are active at the solid / liquid interface, i.e. segregation of $\mathrm{Sr}$ and Al out of the Si crystal and the formation of clusters where the interface acts as a heterogeneous substrate. In the case of conventional solidification, segregation dominates. However, if adsorption of a modifying element ( $\mathrm{Sr}$ or $\mathrm{Na}$ ) is possible, it would be energetically favourable to form clusters at the interface. These clusters are continuously incorporated into the growing Si crystal, which also seals their size and composition. The same reasoning can be used for the alloy modified by $\mathrm{Na}$ with the difference that the compound forming is NaAISi. This means all of the three phases that results from the ternary eutectic reactions (Table I) are present in the alloys, although the $\mathrm{SrAl}_{2} \mathrm{~S}_{\mathrm{i} 2}$ and $\mathrm{NaAISi}$ compounds cannot be resolved by optical microscope or even SEM. It remains unclear whether single modifier atoms or Al-Si-M-rich clusters induce multiplication of crystallographic defect. However, both 
cases highlight the interaction between the modifier and Si. Furthermore, APT shows that Al is present in all defects [16], even when the defect is only one atomic monolayer [18].

The presence of Al-Si-M-rich clusters in the eutectic phase suggests that the efficiency of a modifier depends on its ability to form ternary compound clusters at the Si / liquid interface near the binary eutectic point, and furthers the understanding of the eutectic modification of Al-Si alloys. Other elements such as $\mathrm{Eu}[30,31], \mathrm{Ba}[32], \mathrm{Ca}[33]$ and $\mathrm{Yb}$ [34] which are known to alter the microstructure either to fibrous $\mathrm{Si}$ or a refined plate-like structure can also form ternary compounds, i.e. $\mathrm{EuAl}_{2} \mathrm{Si}_{2}$, BaAlSi, $\mathrm{BaAl}_{2} \mathrm{Si}_{2}, \mathrm{CaAl}_{2} \mathrm{Si}_{2}$ and $\mathrm{YbAl}_{2} \mathrm{Si}_{2}$. Studies of these systems by means of APT will provide additional information towards the understanding of the eutectic modification.

In conclusion, APT chemical analysis showed that $\mathrm{Sr}$ and $\mathrm{Na}$ additions in Al-Si alloys form clusters with fixed and distinctly different Al:M ratios. Based on these results, it is proposed that $\mathrm{SrAl}_{2} \mathrm{Si}_{2}$ and NaAlSi clusters formed at the $\mathrm{Si} /$ liquid interface alter the Si growth and consequently modify the microstructure. This investigation emphasizes the importance of considering compound formation when evaluating elements for modification and optimization of manufacturing processes.

We acknowledge fruitful discussion with Prof. Rainer Schmid-Fetzer, Dr. Songmao Liang and Hisham Aboulfadl. The present investigation is supported by the German Federal Ministry of Economics and Technology (project: AiF 17204 N), the European Regional Development Fund (AME-Lab, C/4-EFRE13/2009/Br), the German Research Foundation (DFG) and the Federal State Government of Saarland (INST 256/298-1 FUGG). The authors thank V. Groten and Prof. Dr.-Ing. A. Bührig-Polaczek (Foundry Institute at RWTH Aachen) for providing samples. J. Barrirero acknowledges the Erasmus Mundus Doctoral Programme DocMASE of the European Commission, N. Ghafoor acknowledges VINNOVA Strategic Faculty Grant VINNMER - Marie Curie Chair for financial support and J.H. Li acknowledges the access to TEM at the Erich Schmidt Institute of Materials Science of the Austrian Academy of Science and the financial support from the Major International (Regional) Joint Research Project (No. 51420105005) from China.

[1] J.E. Gruzleski, B. Closset, The Treatment of Liquid Aluminum-Silicon Alloys, American Foundrymens Society, 1990.

[2] F. Lasagni, A. Lasagni, C. Holzapfel, F. Mücklich, H.P. Degischer, Adv. Eng. Mater. 8 (2006) 719-723. 
[3] L. Clapham, R.W. Smith, J. Cryst. Growth 92 (1988) 263-270.

[4] K. Nogita, H. Yasuda, K. Yoshida, K. Uesugi, a. Takeuchi, Y. Suzuki, a. K. Dahle, Scr. Mater. 55 (2006) 787-790.

[5] S. Lu, A. Hellawell, Metall. Trans. A 18 (1987) 1721-1733.

[6] A. Pacz, Alloy, 1,387,900, 1921.

[7] A.G.C. Gwyer, H.W.L. Phillips, J. Inst. Met. 36 (1923) 283-324.

[8] B.M. Thall, B. Chalmers, J. Inst. Met. 77 (1950) 79-97.

[9] R.C. Plumb, J.E. Lewis, J. Inst. Met. 86 (1958) 393-400.

[10] V.L. Davies, J.M. West, J. Inst. Met. 92 (1963) 175-180.

[11] M.G. Day, A. Hellawell, Proc. R. Soc. A Math. Phys. Eng. Sci. 305 (1968) 473-491.

[12] H. Fredriksson, M. Hillert, N. Lange, J. Inst. Met. 101 (1973) 285-299.

[13] D.C. Jenkinson, L.M. Hogan, J. Cryst. Growth 28 (1975) 171-187.

[14] M.D. Hanna, S.-Z. Lu, A. Hellawell, Metall. Trans. A 15 (1984) 459-469.

[15] K.F. Kobayashi, L.M. Hogan, J. Mater. Sci. 20 (1985) 1961-1975.

[16] J. Barrirero, M. Engstler, N. Ghafoor, N. de Jonge, M. Odén, F. Mücklich, J. Alloys Compd. 611 (2014) 410-421.

[17] M. Timpel, N. Wanderka, R. Schlesiger, T. Yamamoto, D. Isheim, G. Schmitz, S. Matsumura, J. Banhart, Ultramicroscopy 132 (2013) 216-21.

[18] J.H. Li, J. Barrirero, M. Engstler, H. Aboulfadl, F. Mücklich, P. Schumacher, Metall. Mater. Trans. A 46 (2014) 1300-1311.

[19] K. Thompson, D. Lawrence, D.J. Larson, J.D. Olson, T.F. Kelly, B. Gorman, Ultramicroscopy 107 (2007) 131-9.

[20] W. Lefebvre, F. Danoix, G. Da Costa, F. De Geuser, H. Hallem, A. Deschamps, M. Dumont, Surf. Interface Anal. 39 (2007) 206-212.

[21] G. Sha, H. Möller, W.E. Stumpf, J.H. Xia, G. Govender, S.P. Ringer, Acta Mater. 60 (2012) 692-701.

[22] B. Gault, F. de Geuser, L. Bourgeois, B.M. Gabble, S.P. Ringer, B.C. Muddle, Ultramicroscopy 111 (2011) 683-9.

[23] J. Rüsing, J.T. Sebastian, O.C. Hellman, D.N. Seidman, Microsc. Microanal. 6 (2000) 445451.

[24] H.K. Hasting, W. Lefebvre, C. Marioara, J.C. Walmsley, S. Andersen, R. Holmestad, F. Danoix, Surf. Interface Anal. 39 (2007) 189-194.

[25] J.H. Li, M. Albu, F. Hofer, P. Schumacher, Acta Mater. 83 (2015) 187-202.

[26] J.L. Murray, A.J. McAlister, Bull. Alloy Phase Diagrams 5 (1984) 74-84.

[27] N. Bochvar, P. Budberg, F. Hayes, Y. Liberov, R. Schmid-Fetzer, Al-Na-Si Ternary Phase Diagram, MSI, Materials Science International Services GmbH, Stuttgart, 1993.

[28] R. Ferro, O. Kubaschewski, H. Hubert, G. Ibe, VCH 8 (1993) 270-278.

[29] P. Srirangam, S. Chattopadhyay, a. Bhattacharya, S. Nag, J. Kaduk, S. Shankar, R. Banerjee, T. Shibata, Acta Mater. 65 (2014) 185-193.

[30] J.H. Li, X.D. Wang, T.H. Ludwig, Y. Tsunekawa, L. Arnberg, J.Z. Jiang, P. Schumacher, Acta 
Mater. 84 (2015) 153-163.

[31] J. Li, F. Hage, M. Wiessner, L. Romaner, D. Scheiber, B. Sartory, Q. Ramasse, P. Schumacher, Sci. Rep. 5 (2015) 13802.

[32] A. Knuutinen, K. Nogita, S.D. Mcdonald, A.K. Dahle, 1 (2002) 229-240.

[33] T.H. Ludwig, P.L. Schaffer, L. Arnberg, Metall. Mater. Trans. A 44 (2013) 3783-3796.

[34] J.H. Li, S. Suetsugu, Y. Tsunekawa, P. Schumacher, Metall. Mater. Trans. A 44 (2012) 669681.

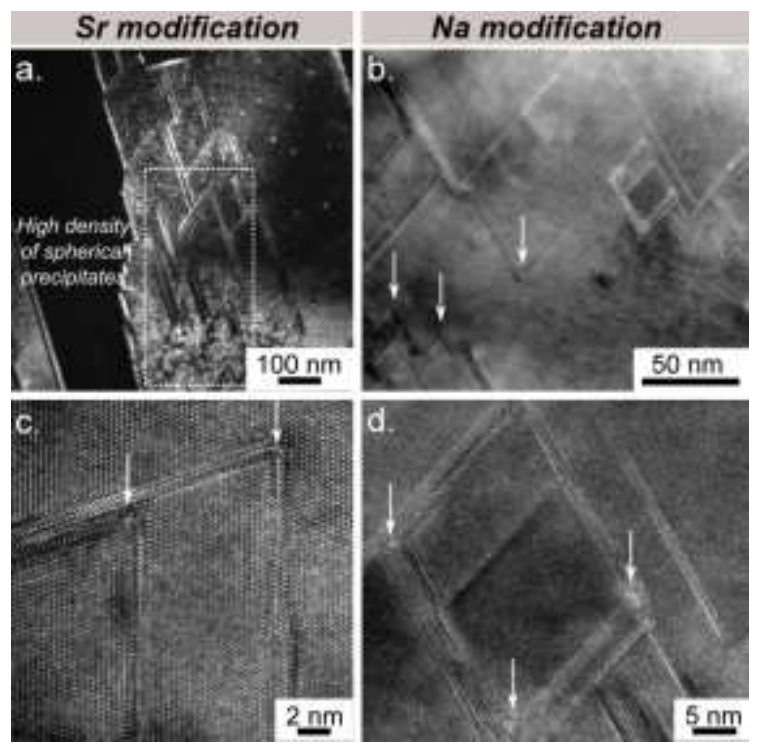

Figure 1: TEM images of the eutectic Si phase. (a) Dark-field image of Sr-modified Si phase recorded along $<111>$ zone axis. (b) Bright-filed image of Na-modified Si phase recorded along $<011>$ zone axis. (c,d) High resolution images of the Sr- and Na-modified alloys, respectively. White arrows highlight particles at the intersections of SFs and TLs.

a.

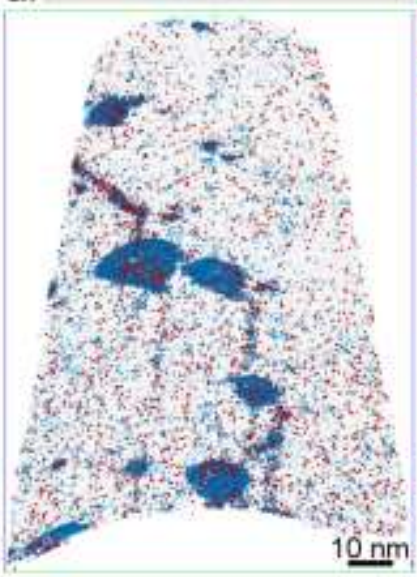

Sr modification

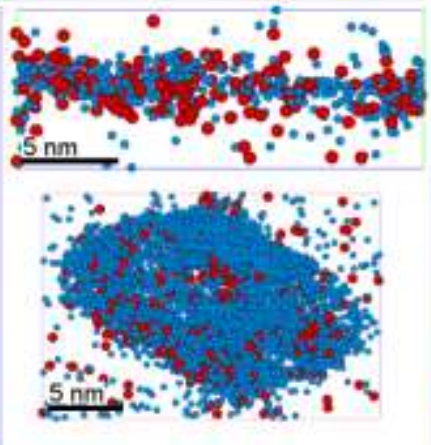

Si OAl Osr b.

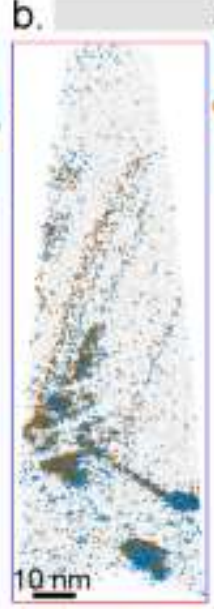

Na modification
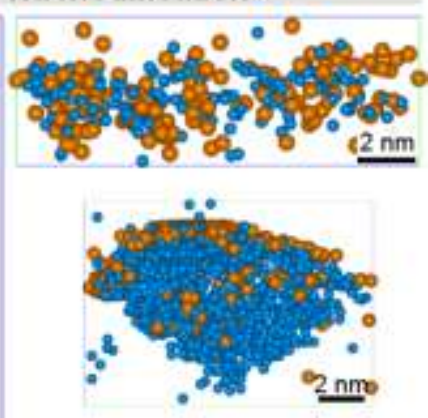

Si OAl $\mathrm{Na}$

Figure 2: APT datasets of the eutectic Si phase and magnified regions of interest of rod-like and particle-like segregations: (a) Sr-modified alloy, b) Na-modified alloy. 


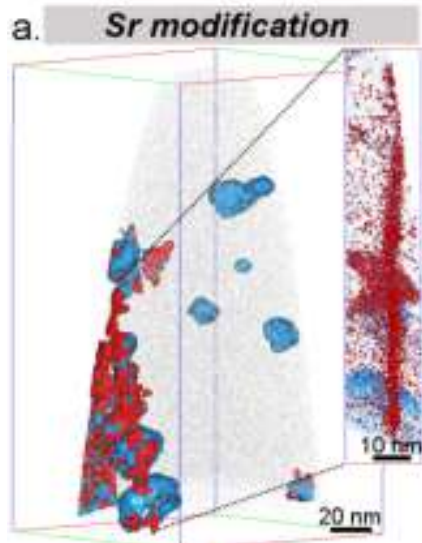

Si Al Pr b. Na modification

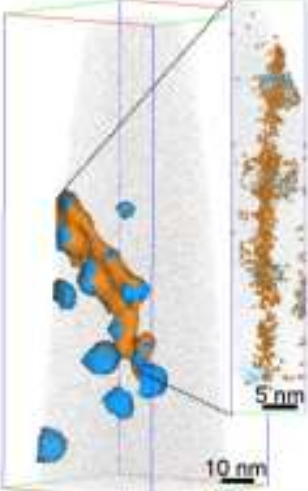

$\bigcirc \mathrm{Si} \bigcirc \mathrm{Al} \bigcirc \mathrm{Na}$

Figure 3: APT datasets of the eutectic Si phase and magnified planar segregations. (a) Sr-modified alloy. (b) Na-modified alloy.

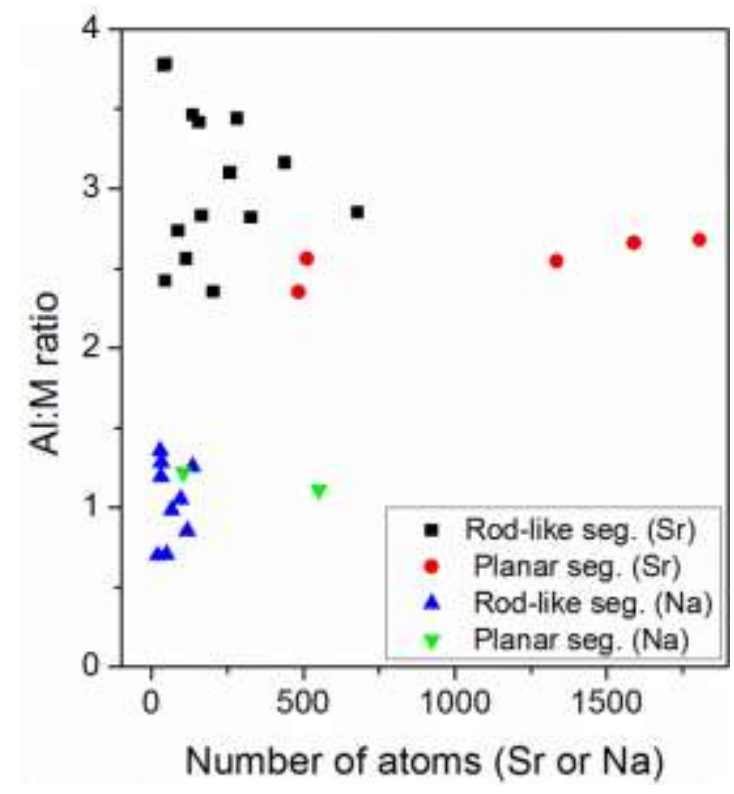

Figure 4: Al:M (M: Sr, Na) ratios for rod-like and planar segregations.

\begin{tabular}{lcccc}
\hline Reaction & $T\left(^{\circ} \mathrm{C}\right)$ & \multicolumn{3}{c}{ Composition (at.\%) } \\
\hline (Al-Si) system [26] & & & $\mathbf{A l}$ & $\mathbf{S i}$ \\
$\mathrm{L} \leftrightarrow(\mathrm{Al})+(\mathrm{Si})$ & 577 & & 87.8 & 12.2 \\
\hline (Al-Si-Na) system [27] & & $\mathbf{N a}$ & $\mathbf{A l}$ & $\mathbf{S i}$ \\
$\mathrm{L} \leftrightarrow \mathrm{AlSiNa}(\mathrm{T})+(\mathrm{Al})+(\mathrm{Si})$ & 576 & 0.01 & 87.35 & 12.64 \\
\hline$(\mathbf{A l}-\mathrm{Si}-\mathrm{Sr})$ system $[28]$ & & $\mathbf{S r}$ & $\mathbf{A l}$ & $\mathbf{S i}$ \\
$\mathrm{L} \leftrightarrow \mathrm{Al}_{2} \mathrm{Si}_{2} \mathrm{Sr}\left(\mathrm{T}_{1}\right)+(\mathrm{Al})+\mathrm{Si}$ & 575 & 0.03 & $\sim 86.8$ & 13.1 \\
\hline
\end{tabular}

Table 1: Eutectic reactions in the binary AI-Si and ternary Al-Si-Na and Al-Si-Sr alloys. 